
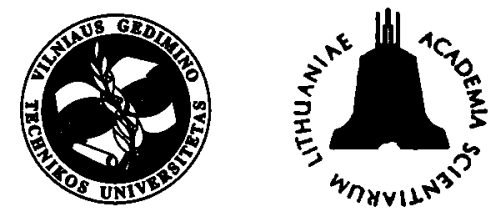

ISSN 1392-3730

\title{
JOURNAL OF CIVIL ENGINEERING AND MANAGEMENT
}

http:/www.vtu.lt/english/editions

2003, Vol LX, No 3, 198-202

\section{WASTE PAPER SLUDGE ASH AND GROUND GRANULATED BLAST FURNACE SLAG AS BINDER IN CONCRETE}

\author{
Albinas Gailius ${ }^{1}$, Živilẻ Laurikietyté2 \\ ${ }^{1}$ Dept of Building Materials, Vilnius Gediminas Technical University, \\ Sauletekio al.11, LT-2040 Vilnius, Lithuania.E-mail: stsm@st.vtu.lt \\ ${ }^{2}$ School of Technology, University of Glamorgan, \\ Pontypridd CF 371 D, United Kingdom. E-mail: zivile@hotmail.com
}

Received 26 June 2001; accepted 23 May 2003

\begin{abstract}
The aim of the research was to develop an economic binder from waste products that could have applications in the production of concrete. Portland cement (PC) production is a very high-energy intensive process that also involves significant environmental damage with respect to $\mathrm{CO}_{2}$ production and raw material acquisition.

This paper investigates workability and strength of concrete made with different proportions of waste paper sludge ash (WSA) and ground granulated blast-furnace slag (GGBS) as binder, at two w/b rations: 0,5 and 0,4 . Specimens were tested unconfined compressive strength after 1, 7,28 and 90 days of curing. The results obtained show that 28 days strength varies between 15-21 MPa, and the general trend of strength development with increasing WSA content has the shape of an inverse parabola, where the highest 28 days and 90 day strengths are achieve by concrete with a mix composition of $50: 50$ at both $w / b$ ratios.

Workability was evaluated by a slump test. Superplasticiser Daracem SP 1 was used for the concrete with WSA - GGBS binder in order to obtain workability, comparable to the observed for concrete with Portland cement binder at equivalent w/b ratio.
\end{abstract}

Keywords: compressive strength, workability, waste paper sludge ash, ground granulated blast-furnace slag.

\section{Introduction}

Portland cement $(\mathrm{PC})$ production is a very high-energy intensive process that also involves significant environmental damage with respect to $\mathrm{CO}_{2}$ production and raw material acquisition [1-3]. In order to reduce the environmental impact of paper manufacture, increasing quantities of paper are being recycled [4-6]. The dry sludge comprises approximately equal amounts of organic and inorganic components, the latter consisting principally of limestone and kaolin [7-9].

The kaolinite content of wastepaper sludge can vary in the range of $15-17 \%$ and the calcite content from $21 \%$ to $70 \%$ [10-12].

The resultant wastepaper sludge ash may have a pozzolanic component, hydraulic component plus nonhydraulic crystalline phases such as anorthite and gehlenite $[7,13]$. Preliminary work has shown it is possible to produce significant cementition by combining wastepaper sludge ash (WSA) with ground granulated blast-furnace (GGBS), a byproduct of the manufacture of pig iron from iron ore $[1,4]$.

The aim of this investigation is to develop an economic binder from wastepaper sludge ash and ground granulated blast-furnace slag that could be applied in the concrete production.

\section{Materials and experimental procedure}

The WSA supplied by Aylesdorf Newsprint Ltd was in the form of a dry powder [14]. It was found necessary to grind the WSA with a view of enhancing hydration [15]. GGBS [16] was supplied by Civil and Marine slag cement Ltd, Newport, UK. In order to obtain workability, comparable to that observed for concrete with Portland cement binder at equivalent $w / b$ ratio, superplasticiser Daracem SP 1 (Grace Construction products, Chelshire, UK) was used. It is based on the soluble salt of polymeric naphalene sulphonate and conforms to type A, D and F materials of ASTM designation C494 [16].

The coarse aggregates were limestone from Aber Kenfic, UK [17]. Sand, dredged from Bristol Channel, was used as fine aggregate and therefore contained some amount of sea salt [18] and seashells [19].

The sieved WSA was ground for 5 minutes in a mixer mill in batches of one kilogram. The resulting WSA 
powder was integrand for one minute with fine GGBS in batches of one kilogram in order to obtain a homogenous mix of desirable mix composition. Dry materials were thoroughly mixed in a CUMFLOW H1-KO4-1526 mixer for 2 min before slowly adding the calculated amount of water. WSA and GGBS were mixed at five different proportions: $30: 70,40: 60,50: 50,60: 40,70: 30$ and at two different $w / b$ ratios: 0,5 and 0,4 .

In the report, the term water/binder $(w / b)$ ratio was used instead of the conventional water/cement ratio to include both the materials mentioned above. After $5 \mathrm{~min}$ of mixing the concrete a slump test [3] was carried out for the purpose of establishing the workability. If the slump was less than $30 \mathrm{~mm}$, a superplasticiser Daracem SPl was added and mixing repeat until the desired workability was obtained. Concrete cubes were cast in $100 \times 100 \times 100 \mathrm{~mm}$ steel moulds. Vibration was carried out immediately after placing the concrete. As the behaviour of each mix composition was different, the time, amplitude and frequency of vibrating were also varied for every mix. The samples were covered with cling film and demoulded at the age of one day after casting, then the cubes inspected and immersed in a curing tank for 1,7 , 28 and 90 days prior to testing for unconfined compressive strength (UCS). The temperature of the water was $20^{\circ} \mathrm{C} \pm 1{ }^{\circ} \mathrm{C}$. At the end of each water curing period three samples were tested. A Denison Mayes Group testing machine No 832118 was used to apply the load at a compression rate of $180 \mathrm{~mm} / \mathrm{min}$.

\section{Results and discussion}

\subsection{Workability}

In order to establish the amount of Daracem SP 1 required for every mix composition the superplasticiser was added to concrete in small doses of $25-50 \mathrm{ml}$. The initial amount established by previous experience was mixed with water and an extra amount required was added directly to concrete during mixing. Table 1 shows the amount of superplasticiser (SP 1) used in every mix composition and its effect on slump.

Very high levels of a superplasticiser were required for binders with high WSA levels. This is because the presence of about $35 \%$ of $\mathrm{CaO}$ in the WSA leads to a

Table 1. Amount of superplasticiser for every mix and its effects on slump

\begin{tabular}{|c|c|c|c|c|}
\hline \multirow{2}{*}{$\begin{array}{c}\text { Mix } \\
\text { WSA:GGBS }\end{array}$} & \multicolumn{2}{|c|}{$\begin{array}{c}\text { Amount of SP 1\% by } \\
\text { weight of binder }\end{array}$} & \multicolumn{2}{c|}{ Slump mm } \\
\cline { 2 - 5 } & 0,5 & 0,4 & 0,5 & 0,4 \\
\hline $30: 70$ & 0 & 6,5 & 42 & 32 \\
\hline $40: 60$ & 3,2 & 8,0 & 38 & 30 \\
\hline $50: 50$ & 3,8 & 9,7 & 35 & 30 \\
\hline $60: 40$ & 3,8 & 9,7 & 34 & 32 \\
\hline $70: 30$ & 8,1 & 18,3 & 58 & 28 \\
\hline
\end{tabular}

very rapid initial hydration and setting. It is anticipated that this problem may be overcome in the future by using appropriate plasticiser/retarder admixtures. It was noticed that the superplasticiser mixed with water dispersed in the concrete much easier and had greater influence on workability compared to that added directly to the concrete during mixing. It is clear that mixes with a w/b ratio of 0,4 had greater demand for the super-plasticiser. The only mix composition $30: 70$ with a w/b ratio of 0,5 had the desired slump without using the superplasticiser. The mix composition 70:30 had the highest demand for superplasticiser at both $\mathrm{w} / \mathrm{b}$ ratios. They were quick to $30: 70$ stiffen. Although the concrete with a $w / b$ ratio of 0,5 seemed fluid enough, it stiffened before completing the filling of the moulds. The concrete with a w/b ratio of 0,4 had a high reactivity and it stiffened before the end of mixing.

\subsection{Strength of concrete}

One-day compressive strength at a $w / b$ ratio of 0,5 for each of the concrete mixes is summarised is Fig 1 .

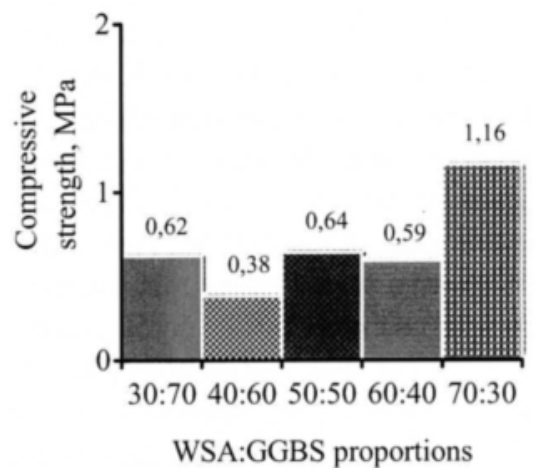

Fig 1. One-day compressive strength; $w / b=0,5$

Each data is the average of three test results. Concrete with WSA-GGBS mix compositions 30:70, 50:50 and 60:40 shows almost identical one-day strength (approximately $0,6 \mathrm{MPa}$ ). The concrete with a mix composition 40:60 shows the lowest strength, which is about two thirds of those described above. The reasons for this are unknown, but it is likely to be due to specimen variability $[9,11]$. Thus, the strength for this mix composition is likely to be close to the other three mixes mentioned.

Concrete with the mix composition 70:30 recorded the highest one-day strength, approximately twice the average recorded for all other mixes. It is not clear, in the case of the concrete with this mix composition, why the high reactivity in the early stages of curing, which caused the improvement of compressive strength is not observed in the closest mix 60:40. However, the one-day strength for the 70:30 mix does not reflect the pattern of strength gain with age as will be seen later. At very early stages they do appear to be a very general trend of increasing strength with increasing amount of WSA although statistical analysis using a much larger sample size would be 


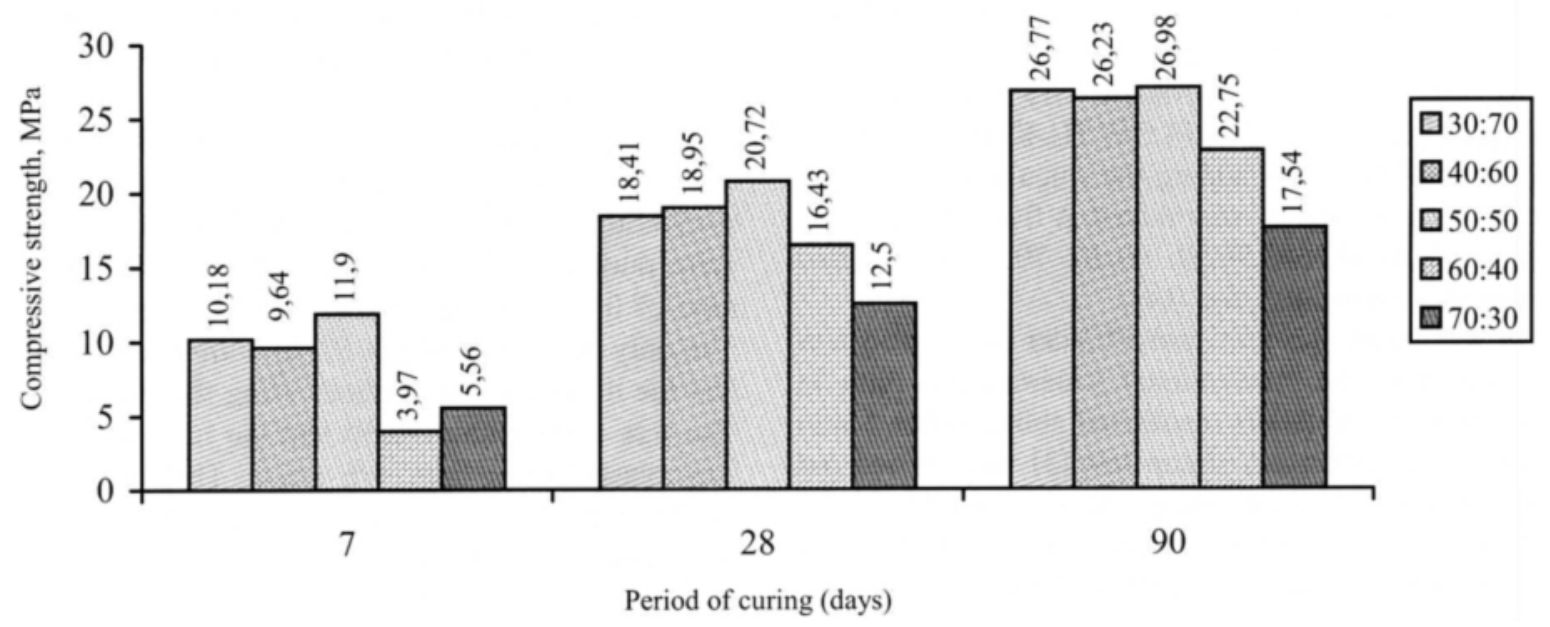

Fig 2. Compressive strength at the age of 7,28 and 90 days of curing; $w / b=0,5$

required to confirm this. This agrees with a similar trend deserved for WSA-GGBS mortar [14, 20, 21].

Fig 2 shows the strength development for various concrete mixes with curing times of up to 90 days. All the mix compositions recorded a very narrow strength variation range at 7 and 28 days of curing from approximately 8-11 MPa for 7 days and 15-19 MPa for 28 days moist-cured specimens. As mentioned earlier, although the one day strength of concrete with mix composition 70:30 was the highest of all mixes, the 7 days and 28 days strength for this mix did not show significant strength enhancement relative to the other mix compositions. In fact, concrete with mix composition 50:50 gained the highest strength of all the mix compositions at all ages beyond one day. In 90 days, the strength of the 50:50 mix concrete is $26,98 \mathrm{MPa}$, which is significantly higher than strengths achieved for all other mixes studied.

From the results obtained, from the age of 7 days onwards, there is no significant strength difference between concrete with $30: 70$ and $70: 30$ mixes, and also between concrete 40:60 and 60:40 binder compositions.

In view of the fact that concrete with mix composition 50:50 obtained the highest strength, it may be argued that WSA and GGBS complement each other as a binder. It is interesting to note that from the age of 7 days, the strength of all mix compositions appear to have mirror symmetry about the 50:50 mix composition. This is more evident at the age of 90 days of curing (Fig 2). Thus, it may be hypothesised that WSA and GGBS more or less equally complement one another, the best result being obtained for concrete with a 50:50 ratio mix composition.

From the age of 1 to 7 days, the strength of concrete with a relatively higher amount of GGBS increased at a generally faster rate compared with that containing a relatively higher amount of WSA. After 7 days, the rate of increase is more or less the same for all mixes. However, in 90 days the 50:50 mix appears to have sustained the highest gains in strength (Fig 2).

Compressive strength at one day for concrete with a $w / b$ ratio of 0,4 is shown in Fig 3. Each data set is again an average of three test results. Strength results show a general trend of increasing strength from the mix composition 30:70 to $70: 30$ (WSA : GGBS) although the concrete with binder composition $60: 40$ is anomalous. This trend was observable, but not as clear with a w/b ratio of 0,5 .

As was observed for $w / b=0,5$, the one-day strength did not reflect the pattern of strength gain with age thereafter. For example, the mix composition 30:70, which recorded the lowest one-day strength, compares favourably with, that of the 40:60 and 50:50 mixes at 7,28 and 90 days of curing.

As pointed out earlier, this also happened with the concrete of a $w / b$ ratio of 0,5 , although the $50: 50 \mathrm{mix}$ composition continued to gain relatively more strength by 90 days. Thus mix composition $70: 30$, which exhibited the highest one-day strength, at the age of seven days, achieves only half the strength achieved by the $30: 70 \mathrm{mix}$ composition, which had recorded the lowest 1-day strength.

As was the case for concrete with a $w / b$ ratio of 0,5, the mix composition 50:50 recorded the highest strength at 7,28 and 90 days of curing although its 90 days strength is not significantly higher than the strength of the $30: 70$ and $60: 40$ mixes. Mixes with rela-

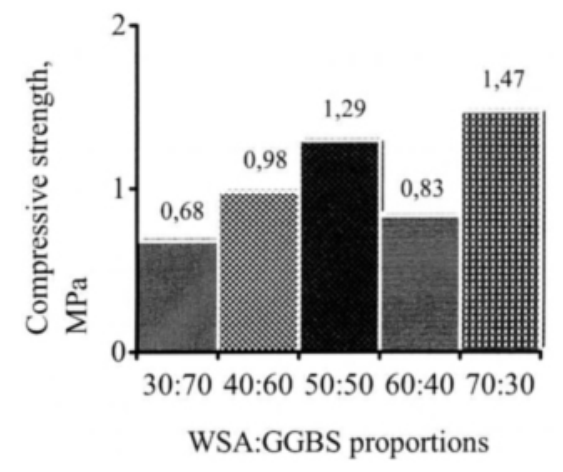

Fig 3. One-day compressive strength; $w / b=0,4$ 
tively higher amounts of GGBS showed greater rates of strength gain from 1-7 days than the high WSA mixes, as was the case for concrete with a w/b ratio of 0,5 . Surprisingly, the maximum strength achieved at 90 days for the $50: 50 \mathrm{mix}$ at a $\mathrm{w} / \mathrm{b}$ ratio of 0,4 is slightly less than with a $w / b=0,5$.

Results indicate that for all mix compositions the one-day strength of concrete with a w/b ratio of 0,4 are generally higher compared with those of concrete with a w/b ratio of 0,5 (Fig 3 and Fig 1). This is not entirely unexpected. Concrete with mix compositions 40:60 and $50: 50$ at $w / b=0,4$ recorded the highest one-day strength increases upon lowering the $w / b$ ratio from 0,5 to 0,4 , respectively 2,6 and 2 times higher strength for the concrete with a w/b ratio of 0,4 . Concrete with a mix composition $70: 30$ at both $w / b$ ratios showed the highest oneday strength development.

Mixes with up to 50:50 WSA-GGBS ratio achieved similar 7-day strength. However, the mixes with relatively higher WSA content $(60: 40$ and $70: 30)$ with a w/b ratio of 0,4 achieved about half the strength of those with a $w / b$ ratio of 0,5 . This is almost certainly due to a relatively higher water requirement, for concrete that is made with increasing WSA-GGBS ratios for the blended binders. This fact is clearly emphasised by the systematic decrease in the ratio of $22,69: 17,54$ on the WSA:GGBS ratio increases. This results is much lower 28 and 90day strength for the 70:30 concrete made at $0,4 \mathrm{w} / \mathrm{b}$ ratio compared with that at 0,5 (Fig 4).

The strength development of concrete made with WSA-GGBS as binder is interior to that made with Portland cement. The rate of early strength development is also much slower for WSA-GGBS concrete, than for PC concrete. The strength data show, for example, that at the age of one day of curing concrete made with PC, achieved about $52 \%$ (for $w / b=0,5$ ) and $71 \%$ (for $w / b=0,4)$ of its strength at the age of 28 days, while the concrete with WSA-GGBS binder achieved only $2-6 \%$ (at both $w / b$ ratios).
Nevertheless, the WSA-GGBS strength at the age is about $53-64 \%$ of the strength at the of 28 days for the concrete with PC binder, that value is about $88 \%$. This indicates that concrete with WSA-GGBS binder gains most of strength between 1-7 days. For both, PC and WSA-GGBS blended binders at the $w / b$ ratio of 0,5 , strength development is marginal beyond 28 days of curing. At a $\mathrm{w} / \mathrm{b}$ ratio of 0,4 , the strength increases from 28 to 90 days are much more significant. Further investigation is required as a low 90 -day strength value was obtained with PC concrete at a $w / b$ ratio of 0,4 , raising the 90 -day relative strengths for WSA-GGBS concrete at a $w / b$ ratio of 0,4 .

\section{Conclusions}

1.The results obtained show that it is possible to combine WSA and GGBS, a waste product and a byproduct respectively, to produce a binder without incorporating Portland cement.

2. The unconfined compression strength obtained for WSA-GGBS concrete were for some compositions close to $50 \%$ of the equivalent values obtained for Portland cement concrete. It is anticipated that further research will increase this figure. The rate of development of strength of concrete made with WSA-GGBS binder achieved 1-day strength of about $2-6 \%$ of its 28-day strength, while the 7-day strength was in the range $53-64 \%$ of the 28-day strength. This indicates that WSA-GGBS concrete gains most strength between 1-7 days.

3. Although concrete with a binder mix composition of 70:30 at both $w / b$ ratios showed the highest one-day strength of all the mixes, from the age of 7 days onwards, this mix showed the lowest strength development compared with the other mix compositions.

4.WSA and GGBS in the WSA-GGBS blended binder appear to contribute to the binary blend hydration in such a manner that concrete with the mix

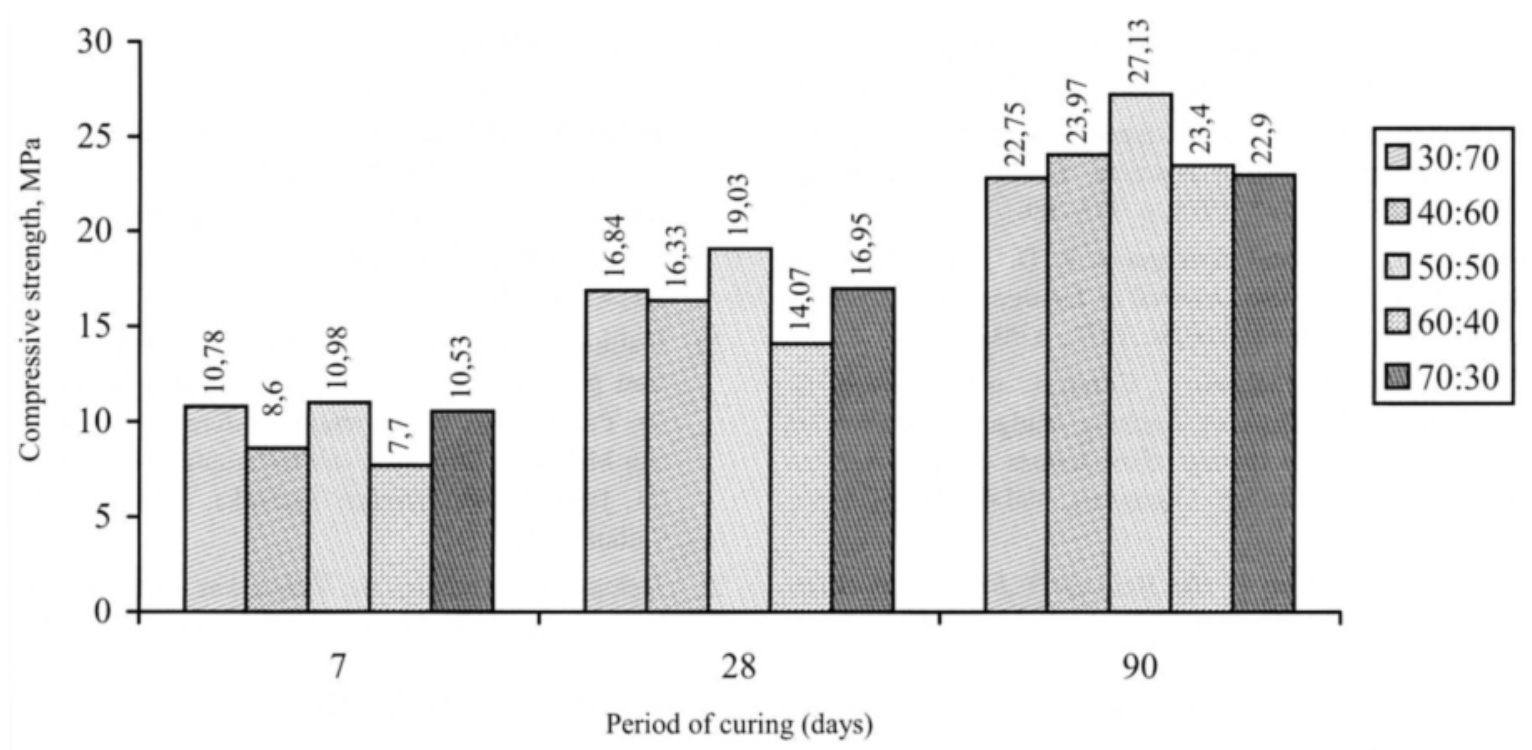

Fig 4. Compressive strength at the age of 7,28 and 90 days of curing; $w / b=0,4$ 
composition 50:50 (WSA:GGBS) at both $w / b$ ratios gained the highest strength beyond one day.

5. Strengths of WSA-GGBS concrete mixes with a $w / b$ ratio of 0,4 as expected are generally higher than those of concrete with a w/b ratio of 0,5 . However, the mixes with a relatively higher WSA content $(60: 40$ and $70: 30$ ) with $a w / b$ of 0,4 achieved only about half the strength of those with a w/b ratio of 0,5 . This is thought to be due to an increased water requirement for concrete mixes made with high WSA:GGBS blend ratios.

6. Only one mix composition $30: 70$ obtained a desirable slump without the use of a superplasticiser. The demand of superplasticiser generally increased with the amount of WSA. Mix composition 70:30 had the highest demand for superplasticiser at both $w / b$ ratios. Although mix composition with high WSA content seemed fluid enough for compaction and achieved, after adding superplasticiser reasonable slumps, they stiffened before the end of placing the concrete into moulds.

7. All WSA-GGBS concrete mixes stiffened far more quickly than those made of concrete with Portland cement as binder did. Test results of paste have shown that the problem of setting time may be eliminated by using retarders. Results also indicate that the problem of workability, with concrete may be overcome by the use of superplasticisers. Further research is however needed to establish how all the required superplasticiser may be added at once in the water used for mixing. Also, further investigation into the use of superplasticiser and retarder is required, in order to simultaneously solve the problem of low workability and of the quick setting time.

\section{References}

1. Tazawa, Y.; Ohomoto, T.; Taira K. Properties of anti-washout concrete with high blast-furnace slag content. In: Malhotra VM, editor. Proceedings of Third International Conference on Fly Ash, Silica Fume, Slag and Natural Pozzolans in Concrete. Trondheim, Norway, ACJ SP, Vol 114, No 2, 1989, p. 1615-1636.

2. Taylor, H. F. W. Cement Chemistry, $2^{\text {nd }}$ edition. Published: Thomas Telford Publishing, 1997, p. 116-122, 184-189.

3. Naik, T. R. Effect of cement types in accelerated compressive strength testing of concrete. Cement and Concrete Research, Vol 9, No 3, 1979, p. 377-386. ISSN 0008-8846

4. Anderson, R. C. and Spielgman, R. D. Tax policy and secondry material use. Journal of Environmental Economics and Management, Vol IV, 1977, p. 68-82.

5. Trepamier, L.; Gallichand, J.; Caron, J. and Theriault, G. Environmental effects of deinking sludge application on soil and soil water quality. Transactions of the American Society of Agricultural Engineers, Vol 41, No 5, 1998, p. 1279-1287.

6. Coggins, P. C. Who is the Recycler? Journal of Waste Management and Resource Recovery, Vol 1, No 2, 1994, p. 69-75.

7. Taylor, J. S.; Tucker, P. and Allison, S. M. An investigation into the biodegradation of newsinks in relation to deinking sludge waste management. Environmental and Waste Management, No 3(1), 2000, p. 1-9.

8. Kazragis, A.; Gailius, A.; Juknevičiūtè, A. Thermal and acoustical insulating materials containing mineral and polymeric binders with celluloses fillers. Materials Science, Vol 8, No 2. Kaunas: Technologija, 2002, p. 193-195. ISSN 1392-1320.

9. Seboh, T. Relationships between the properties of lignasulphonates and parameters of modified samples with cement binders. Cement and Concrete Research, Vol 30, No 4, 2000, p. 511-515.

10. Wild, S.; Gailius, A. Pozzolanic properties of a variety of European clay bricks. Building research and Information, Vol 25, No 3, 1997, p. 18-25. ISSN 0961-3218.

11. Hyvarinen, E. Paper recovery in Europe: Industrial views. In: Exploiting wastes in concrete. Edited by Ravindra K. Dhir and Trevor G. Jappy. Published by Thomas Telford Publishing, Thomas Telford Ltd, London, 2001, p. 1-8.

12. Liaw, C. T.; Chang, H.; Hsu, W. C. and Huang, C. R. A novel method to reuse paper sludge and co-generation ashes from paper mill. Journal of Hazardous Materials, Vol 58, No $1-3,1998$, p. 93-102.

13. Tucker, P.; Taylor, J. S.; Durrant, A. P. Environmental research for the newspaper industry. Paper technology. Vol 40, No 10, 1999, p. 51-61.

14. Kinuthia, J. M.; Gailius, A.; Laurikietyté, Ž. Compressive strength and workability of concrete utilizing waste-paper sludge ash and ground granulated blast furnace slag as binder. In: Proceedings of $7^{\text {th }}$ intern conference "Modern Building Materials, Structures and Techniques", held on May 16-18, 2001. Vilnius: Technika, 2001, [CD-ROM], p. 117-119.

15. Modry, S. Use of waste paper as a constituent of concrete. Edited by Ravindra K. Dhir and Trevor G. Jappy. Published by Thomas Telford Publishing. Thomas Telford Ltd., London, 2001, p. 77-81.

16. British Standard Institution (1982) BS 5075: Part 1: Specification for accelerating admixtures, retarding admixtures and water reducing admixtures. Part 3: Specification for superplastizing admixtures. BSI, February, 1982.

17. British Standard Institution. Testing Aggregate. BS 812 . Part 100: 1990; Part 117: 1988.

18. British Standard Institution (1997) BS 8110: Part 1: Structural use of concrete. BSI, March 1997.

19. British Standard Institution (1992) BS 882: Specification for aggregates from natural sources for concrete. BSI, December 1992.

20. Gailius, A.; Vislavičius, K.; Žukauskas, D. Some optimization problems of the aggregates composition of concrete. In: Proceedings of $6^{\text {th }}$ intern conference "Modern Building Materials, Structural and techniques", held on May 1921, 1999, Vol IV. Vilnius: Technika, 1999, p. 158-162 (in Lithuanian).

21. Delpak, R.; Gailius, A.; Žukauskas D. Determination of thermal-mechanical properties of concrete. Journal of Civil Engineering and Management, Vol VIII, No 2. Vilnius: Technika, 2002, p. 121-124. 